\title{
Arachnoid nodules in the lungs of high altitude Indians
}

Donald Heath, David Williams

\begin{abstract}
Background-Nodules of cells showing a striking histological similarity to those of arachnoid villi have previously been found closely adjacent to pulmonary venules in several diseases associated with alveolar hypoxia or pulmonary oedema including mitral stenosis, plexogenic pulmonary arteriopathy, pulmonary thromboembolism, and chronic obstructive pulmonary disease.

Methods-Histological sections of the lungs of seven adult native highlanders from La Paz (3600 m) were examined.

Results-Arachnoid nodules were found in the lungs of one Aymara and one Mestizo Indian.

Conclusions-These bodies may have a similar function to that of arachnoid granulations which transfer excess cerebrospinal fluid to the dural venous sinuses. In the native highlanders it is possible that they contribute to the avoidance of excessive hydration of the interstitial tissue of the alveolar walls with return of fluid into the pulmonary venules, preventing incipient pulmonary oedema.
\end{abstract}

(Thorax 1993;48:743-745)

In a recent review of histological sections of lung from Indians living at high altitude we found nodules of lung resembling arachnoid villi similar to those reported previously in several conditions associated with alveolar hypoxia or pulmonary oedema..$^{1-3}$ These cellular structures have been seen before in

Age, sex, ethnic origin (Aymara/Mestizo), main diagnosis at necropsy, and components of pulmonary vascular remodelling in the cases studied.

\begin{tabular}{|c|c|c|c|c|c|c|c|}
\hline \multirow[b]{2}{*}{$\begin{array}{l}\text { Case } \\
\text { no. }\end{array}$} & \multirow[b]{2}{*}{$\begin{array}{l}\text { Ethnic } \\
\text { origin }\end{array}$} & \multirow[b]{2}{*}{$\begin{array}{l}\text { Agel } \\
\text { sex }\end{array}$} & \multirow[b]{2}{*}{$\begin{array}{l}\text { Main diagnosis } \\
\text { at necropsy }\end{array}$} & \multicolumn{4}{|c|}{ Presence of pulmonary vascular lesions } \\
\hline & & & & $\begin{array}{l}\text { Arachnoid } \\
\text { nodules }\end{array}$ & $M u$ & $L m$ & $M t$ \\
\hline 1 & $\mathbf{A}$ & $28 / M$ & Cerebellar tumour & + & + & + & + \\
\hline 2 & A & $37 / \mathbf{M}$ & $\begin{array}{l}\text { Peritonitis; } \\
\text { ruptured appendix }\end{array}$ & 0 & + & 0 & 0 \\
\hline 3 & A & $42 / M$ & Gastric lymphoma & $\mathbf{0}$ & + & 0 & 0 \\
\hline 4 & $\mathbf{M}$ & $15 / F$ & Lupus erythematosus & 0 & 0 & 0 & $\mathbf{0}$ \\
\hline 5 & $\mathbf{M}$ & $15 / M$ & Rabies & 0 & 0 & + & 0 \\
\hline 6 & $\mathbf{M}$ & $32 / \mathrm{M}$ & Bacterial endocarditis & 0 & + & 0 & 0 \\
\hline 7 & $\mathbf{M}$ & $32 / \mathrm{M}$ & Pyelonephritis & + & 0 & 0 & 0 \\
\hline
\end{tabular}

A-Aymara; $\mathrm{M}$-Mestizo; $\mathrm{Mu}$-muscularisation of pulmonary arterioles; $\mathrm{Lm}$-longitudinal muscle in intima of pulmonary artery; $\mathrm{Mt}-$ muscular tubes. cases of systemic hypertension ${ }^{4}$ and primary plexogenic pulmonary arteriopathy. ${ }^{5}$ In this paper we give an account of the existence of these nodules in Aymara Indians of the Bolivian Andes and speculate on their function.

\section{Methods}

Both lungs were obtained at necropsy from seven adult native highlanders from $\mathrm{La} \mathrm{Paz}$. All had been born and spent most of their lives at an altitude of $3600 \mathrm{~m}$ or more in the Bolivian Andes. Details of age, sex, ethnic background, the major disease found at necropsy, and the type of pulmonary vascular remodelling are shown in the table. Care was taken to exclude cases of cardiopulmonary disease. It is usually difficult to acquire even small specimens of human lung from native highlanders in the Andes so it was an unusual privilege to obtain both entire lungs from three Aymaras and four Mestizos.

Both lungs were distended with $10 \%$ formalin until the pleural surfaces were smooth. Three blocks of lung were resected from each of the three lobes of the right lung and the upper and lower lobes of the left lung. These blocks of tissue were embedded in paraffin wax so that 15 blocks of lung tissue were available for study in each of the seven cases included in the investigation. Paraffin sections, $4 \mu \mathrm{m}$ in thickness, were prepared and stained with haematoxylin and eosin and by the elastic van Gieson method. A detailed search of the sections was made for arachnoid nodules situated in the interstitial tissues of alveolar walls closely adjacent to pulmonary venules.

A histological study was also made of the small pulmonary arteries and pulmonary arterioles for evidence of pulmonary vascular remodelling which is known to occur in native highlanders in response to the hypobaric hypoxia of high altitude. ${ }^{67}$ Particular attention was paid to the presence of muscularisation of pulmonary arterioles, intimal longitudinal muscle in the pulmonary arteries, and the development of inner muscular tubes in the lumens of the pulmonary arteries and arterioles. ${ }^{7}$

\section{Results}

Small cellular nodules, $140-150 \mu \mathrm{m}$ in diameter, apparently arising from the interstitial tissues of alveolar walls and closely adjacent 
to pulmonary venules were found in cases 1 and 7. One or two nodules were found in most but not all blocks in these cases. They were round or oval and their outer surfaces were covered by pulmonary capillaries (fig 1). Centrally situated in each nodule was a pulmonary venule containing erythrocytes. This was embedded in a mass of cells forming the nodule with large round or oval nuclei with punctate heterochromatin (figs 1 and 2). They have a striking resemblance to cells of the arachnoid villi and granulations protruding into the dural sinuses overlying the brain. The plentiful cytoplasm of these cells was palely eosinophilic and, in many instances, was distended by large vacuoles which clustered around the nuclei (figs 1 and 2). From the walls of some venules minute channels led back into the surrounding mass of arachnoid cells distended with vesicles (fig 2). These channels were lined by cells with elongated nuclei showing a dense chromatin pattern and thus quite distinct from the nuclei of arachnoid cells. The nodules in case 1 were reminiscent of those described by Churg and Warnock. ${ }^{3}$ There was a central nodule of arachnoid cells with strands extending into the adjacent thickened alveolar walls. The surrounding alveolar spaces were increased in size.

Figure 1 Case 7 Arachnoid nodule showing its general configuration. It arises from the interstitial tissues of alveolar walls and is covered by pulmonary capillaries (c). In the centre of the body is a venule $(v)$. The substance of the body is formed of arachnoid cells. Stain: haematoxylin and eosin.

Figure 2 Case 7. Part of the arachnoid body shown in fig 1 at higher magnification to show cytological detail. Opening into the central venule (v) is a narrow canal (ch) lined by cells with elongated nuclei. Immediately adjacent to these nuclei the underlying cytoplasm contains small vacuoles. The cells around the venule are arachnoid with large round or oval nuclei showing punctate heterochromatin and surrounding vacuolated cytoplasm (small arrows). Stain: haematoxylin and eosin.
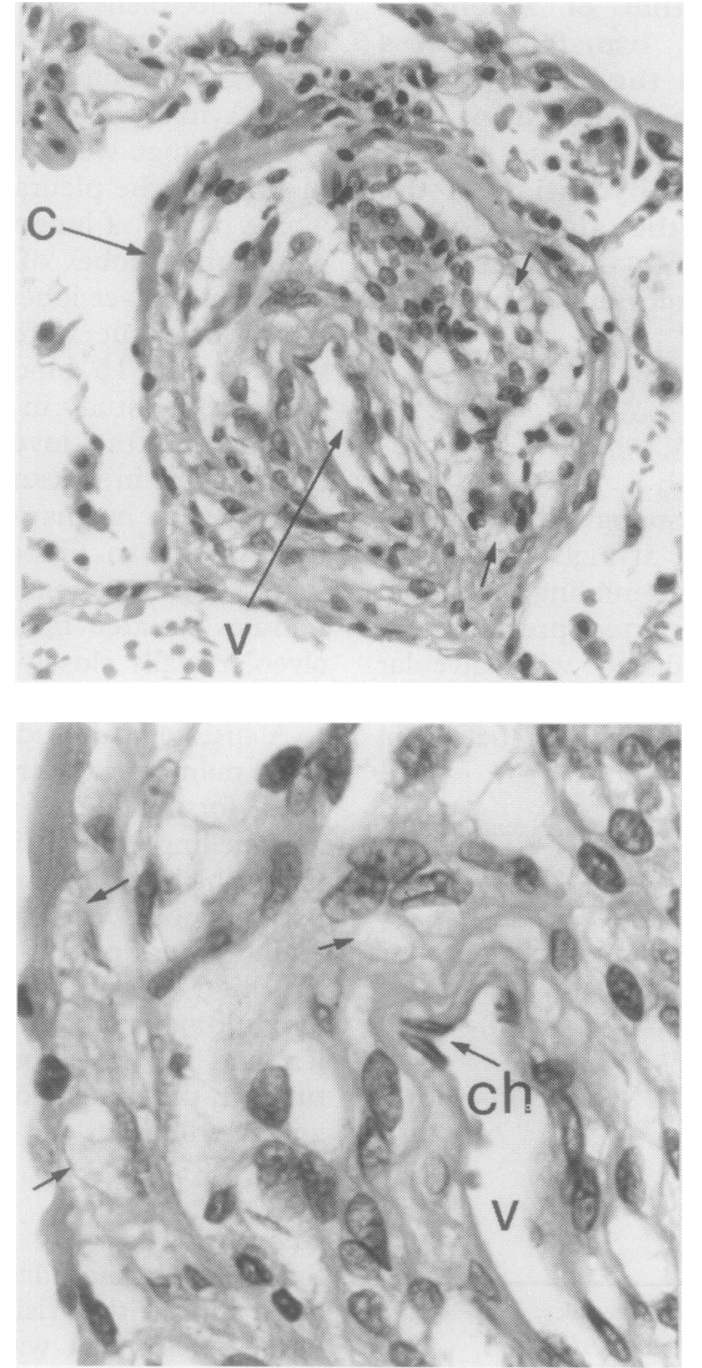

Pulmonary vascular remodelling was found in five of the seven cases (table 1). Muscularisation of the pulmonary arterioles was found in four cases, the development of intimal longitudinal muscle in the small pulmonary arteries in two, and the formation of inner muscular tubes in one. In the two cases which showed arachnoid nodules, case 1 (an 음 Aymara Indian) showed all three components $\underset{\times}{\stackrel{0}{*}}$ of the triad of pulmonary vascular remodelling while case 7 (a Mestizo) had a normal $\stackrel{5}{?}$ pulmonary vasculature (table).

\section{Discussion}

When sections of lung taken routinely at necropsy at low altitude are studied histologi- $\overrightarrow{0}$ cally one very occasionally comes across small $\overrightarrow{-}$ nodules of tissue around pulmonary venules $\vec{\sigma}$ that at first sight appear to be glomic in $\overrightarrow{\vec{*}}$ nature. These were considered to be chemo- $x$ receptor in nature by Korn et $a l^{1}$ who described several hundreds of them in all $v$ lobes in one case as "multiple minute pul- $\vec{\omega}$ monary tumours resembling chemo-음 dectomas." These nodules are small and, in one case previously reported, ${ }^{4}$ measured up to $c$ $1.0 \times 0.6 \mathrm{~mm}$ in diameter. They are situated $\underset{ }{\gtrless}$ mainly in the peripheral portions of the lung, $\vec{\bullet}$ especially at the insertions of septa into the pleura.

Electron microscopy has subsequently revealed that the constituent cells do not contain dense core vesicles in their cytoplasm, indicating that they are not, in fact, chief $\frac{\mathbb{Q}}{\mathscr{Q}}$ (type I) chemoreceptor cells. ${ }^{23}$ Instead they $\overrightarrow{\overrightarrow{0}}$ contain tangled cytoplasmic fibrils, 6-10 nm 3 in width, and show complex interdigitation between adjoining cells which are kept adher-? ent by desmosomes. Such ultrastructural appearances were consistent with the surpris- $\frac{}{2}$ ing conclusion that the tissue around the pul- $x$ monary venules was, in fact, composed of $\frac{5}{3}$ arachnoid cells identical to those comprising the arachnoid villi and granulations in close $\frac{0}{3}$ contact with the dural sinuses overlying the brain.

The concept of meningeal-like tissue $\frac{D}{O}$ around pulmonary venules seemed remarkable, but subsequent examination of more of $N$ these nodules has confirmed their arachnoid N nature. We have recently reported their pres- N ence in a case of primary plexogenic pulmonary arteriopathy ${ }^{5}$ and found the tissues to form clusters of whorled cells identical to $\mathbb{D}$ those found in normal arachnoid villi or in $\stackrel{\oplus}{+}$ meningiomas. In that case the nodules insin- 0 uated into the lumen of pulmonary venules $\frac{\vec{D}}{\mathbb{D}}$ up to $80 \mu \mathrm{m}$ in diameter. The nodules com- $\stackrel{\Phi}{\stackrel{\Phi}{\oplus}}$ posed of arachnoid-like cells appear to arise $\stackrel{\AA}{\circ}$ from the interstitial tissues of alveolar walls adjacent to pulmonary venules. Commonly $ᄋ$ the bulk of the tissue forms a central mass? from which radiate alveolar septa thickened

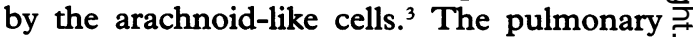
capillaries are stretched over the constituent cells so that the displaced capillary loops separate the cells from the alveolar spaces.

Our studies show that the presence of arachnoid nodules in the lungs of a highlander 
is not associated with pulmonary vascular remodelling related to chronic exposure to the hypobaric hypoxia of high altitude (table). In case 1 the nodules occurred in an Aymara Indian who showed all three of the triad of changes previously described by us, ${ }^{67}$ namely muscularisation of pulmonary arterioles, intimal longitudinal muscle in the intima of small pulmonary arteries, and inner muscular tubes in the lumen of pulmonary arteries. In contrast, in case 7 the nodules occurred in a Mestizo Indian who had a normal pulmonary vasculature.

These arachnoid nodules occur in the normal lung at low altitude but are not found very frequently. Personal experience in our laboratory is in keeping with reports in the literature that they are to be found in about $0.5 \%$ of lung sections taken for routine histological examination at necropsy. ${ }^{8}$ Dail $^{9}$ suggested that, once one is aware of these lesions, they may be found in about one in $\mathbf{4 0}$ lung specimens derived from necropsies or surgical histopathology. This has not been our experience over the past 20 years, since we have been familiar with this entity, and we are not aware of any laboratory in the UK which reports such a high incidence. We found arachnoid nodules in two of seven native highlanders. Our investigation was carried out in only a small group of Indians but this is an inherent drawback to field work at high altitude. It is impossible to acquire both entire lungs for study in a large series of Aymara and Mestizo Indians to assess the incidence of such entities. Nevertheless, our field work has shown for the first time that arachnoid nodules are to be found, and should be sought, in the lungs of native highlanders.

Arachnoid nodules in normal lungs may have a minor physiological function but they seem to be prominent in certain diseases where this function may assume greater importance. They have been commonly reported in cases of chronic bronchitis and emphysema where it was thought that the chronic alveolar hypoxia might have led to a hyperplastic response of the supposed chemoreceptor tissue of these nodules. ${ }^{3}$ However, the subsequent recognition of these nodules as arachnoid in nature raises the possibility that they are in some way a reaction to the sodium retention and oedema which characterises "blue bloaters." It is interesting that arachnoid nodules occur in the lung of native highlanders where there is also chronic alveolar hypoxia, although as the result of diminished barometric pressure rather than of pulmonary disease. Lung oedema is a common feature of mitral stenosis, another disease in which pulmonary arachnoid nodules are often found. We have reported them in a case of primary plexogenic arteriopathy. ${ }^{5}$ In this disease there are commonly exudative changes in the lung parenchyma ${ }^{10}$ with the accumulation of mast cells in the alveolar spaces. ${ }^{1011}$

This association with incipient lung oedema leads us to speculate that the arachnoid-like cells forming the nodules adjacent to the pulmonary venules may have a function similar to that of the arachnoid villi and granulations in the meninges which absorb cerebrospinal fluid and return it to the dural venous sinuses. It is possible that fluid from the interstitial tissues of the alveolar walls is absorbed by arachnoid cells which show oedema of their cytoplasm (figs 1 and 2). The fluid may be passed on through channels between the arachnoid cells in the thickened alveolar walls to the central arachnoid nodule. Here it appears to be passed through conduits lined by elongated, dark cells into the blood in the pulmonary venules (fig 2). In the arachnoid nodules in the lung of the case of plexogenic pulmonary arteriopathy ${ }^{5}$ some of the venules draining the nodules were up to $80 \mu \mathrm{m}$ in diameter (fig 1 in ref 5).

This possible association between arachnoid nodules in the lung and pulmonary oedema led us to search for them in the lungs of native highlanders. In lowlanders ascending to high altitude sodium and water retention is an important physiological disturbance which is thought to underlie the development of acute mountain sickness and its serious and sometimes fatal complications of cerebral oedema and high altitude pulmonary oedema. Pulmonary oedema is a constant risk for native highlanders, especially if they take a brief descent to a lower altitude. Complex endocrinological factors occur to prevent excessive sodium retention and hydration and these are associated with histological changes-for example, a decrease of aldosterone secretion is associated with thinning of the zona glomerulosa of the adrenal gland. We have previously described sodium homeostasis and hydration in subjects at high altitude and have listed the many contributory factors to both the causation and prevention of lung oedema. ${ }^{12}$ We believe that in native highlanders these arachnoid nodules may contribute to maintaining the hydration of the interstitial tissues of the alveolar walls within safe limits.

1 Korn D, Bensch K, Liebow AA, Castleman B. Multiple minute pulmonary tumors resembling chemodectomas. Am f Pathol 1960;37:641-72.

2 Kuhn C, Askin FB. The fine structure of so-called minute pulmonary chemodectomas. Hum Pathol 1975;6: 681-91.

3 Churg AM, Warnock ML. So-called "minute pulmonary chemodectoma". A tumor not related to paragangliomas. Cancer 1976;37:1759-69.

4 Edwards C, Heath D. Pulmonary venous chemorecepto tissue. $B r f$ Dis Chest 1972;66:96-100.

5 Heath D, Smith $P$. Nodules resembling arachnoid villi in pulmonary venules in plexogenic pulmonary arteriopathy. Cardioscience 1992;3:161-5.

6 Heath D, Williams D, Rios-Dalenz J, Calderon M Gosney J. Small pulmonary arterial vessels of Aymara Indians from the Bolivian Andes. Histopathology 1990;16:565-71.

7 Heath D, Williams D. Pulmonary vascular remodelling in a high-altitude Aymara Indian. Int $f$ Biometeorol 1991;35:203-7.

8 Thurlbeck WM. Neoplasia of the pulmonary vascular bed. In: Moser KM ed, Pulmonary vascular disease. New York, Basel: Marcel Dekker, 1979;629-49.

9 Dail DH. Uncommon tumors. In: Dail DH, Hammar SP, eds. Pulmonary pathology. New York: Springer Verlag, 1988:903-10

10 Caslin AW, Heath D, Madden B, Yacoub M, Gosney JR, Smith P. The histopathology of 36 cases of plexogenic pulmonary arteriopathy. Histopathology 1990;16:9-19.

11 Heath D, Yacoub $M$. Lung mast cells in plexogenic pulmonary arteriopathy. 9 Clin Pathol 1991;44:1003-6.

12 Heath D, Williams DR. High-altitude medicine and pathology. London: Butterworths, 1989. 